32. Bell WR, Pitney WR, Goodwin JF. Therapeutic defibrination in the treatment of thrombotic disease. Lancet 1968;1:490493.

33. Belch JJC, Meek DR, Lowe G, Meek DR, Campbell AF, Young AB, Forbes CD, Prentice CRM. Subcutaneous ancrod in prevention of deep venous thrombosis after hip surgery. Thromb Res 1982;25:23-31.

34. Dormandy JA, Reid HL. Controlled defibrination in the treatment of peripheral vascular disease. Angiology 1978; 29:80-88.

35. Sharp AA, Warren BA, Paxton AM, Allington MJ. Anticoagulant therapy with a purified fraction of Malaysian pit viper venom. Lancet 1968;1:493-499.

36. Davies JA, Sharp AA, Merrick MV, Holt JM. Controlled trial of ancrod and heparin in treatment of deep-vein thrombosis of lower limb. Lancet 1972;1:113-115.

37. Leon MB, Cannon RO, Watson RM, Rosing DR, Epstein SE. Long-term clot-specific thrombolytic therapy in patients with refractory chronic stable angina: Angiographic, coronary blood flow, and metabolic changes (abstr). Circulation 1984;70:11-323.

38. Willerson JT, Campbell WB, Winniford MD, Schmitz $J$, Apprill P, Firth B, Ashton J, Smitherman T, Bush L, Buja LM. Conversion from chronic to acute ischemic heart disease. Speculation regarding mechanisms. Am J Cardiol 1984; 54:1349-1354.

39. Bush LR, Campbell WB, Kern K, Tilton GD, Apprill P, Ashton J, Schmitz J, Buja LM, Willerson JT. The effects of alpha-2-adrenergic and serotoninergic receptor antagonists on cyclic blood flow alterations in stenosed canine coronary arteries. Circ Res 1985;55:642-652.

40. Hamsten A, Wiman B, de Faire U, Blomback M. Increased plasma levels of a rapid inhibitor of tissue plasminogen activator in young survivors of myocardial infarction. $\mathrm{N}$ Engl J Med 1985;313:1557-1563.

\title{
Relation between greded, subcritical impairments of coronary flow reserve and regional myocardial dyefunction induced by isoproterenol infusion in dogs
}

\begin{abstract}
Isoproterenol has been used experimentally and clinically to elicit ischemia. The usefulness of this approach, however, in eliciting regionel dyafunction in the presence of mild to moderate single-vessel coronary disease quantitated on the basis of coronary flow reserve measurements has not been previously defined. Open-chest, anesthetized dogs were instrumented with an electromagnetic flow probe, high-fidelity micromanometers, and subendocardiat ultrasonic crystals. A rigid, screw occluder was used to produce five subcritical coronary stenoses in each dog aseociated with varying impairment of postoccluaion reactive hyperemia at rest but no impairment of resting coronary blood flow. Regional function at rest and in response to the isoproterenol challenge $(0.25 \mu \mathrm{g} / \mathrm{kg} / \mathrm{min})$ in nonstenotic and stenotic conditions was assessed. Relative regional function was maintained during the infusion untll nearly total loss of coronary flow reserve. With this near-critical stenosis, function was lower than in the nonstenotic state but remained greater than resting control values. Moderate impairments of coronary flow reserve were not associated with isoproterenof-Induced deterloration of regional function. In conclusion, detection of impaired coronary flow reserve at rest is a more seneitive index of the severity of a coronary stenosis than is detection of regional dysfunction during leoproterenol chalienge. Fallure to maintain the expected isoproterenof-induced increase in regional function is manifested only when stenoses are essociated with nearly total loss of resting coronary flow reserve. This suggeste that the clinical use of isoproterenol challenge is not effective in eliciting regional dysfunction when mild coronary disease is present. (Am HeART J 1987;113:906.)
\end{abstract}

\author{
G. B. John Mancini, M.D., F.R.C.P.(C), Harold Z. Friedman, M.D., \\ John E. Hramiec, B.A., and Scott F. DeBoe, B.S. Ann Arbor, Mich.
}

From the Department of Internal Medicine, Division of Cardiology, Veterans Administration Medical Center, University of Michigan Medical School.

Supported in part by funds from the Veterans Administration, Washington, DC, and the American Heart Association of Michigan, Lathrup Village, MI.
Received for publication April 11, 1986; accepted Aug. 11, 1986.

Reprint requests: G. B. John Mancini, M.D., F.R.C.P.(C). University of Michigan Medical School, Veterans Administration Medical Center, 2215 Fuller Rd., Ann Arbor, MI 48105. 
Table I. Hemodynamics at rest and during isoproterenol infusions in the presence and absence of coronary stenoses: Part A

\begin{tabular}{|c|c|c|c|c|c|}
\hline & \multirow[b]{2}{*}{ Control } & \multicolumn{4}{|c|}{ Isoproterenol infusion $(0.25 \mu \mathrm{g} / \mathrm{kg} / \mathrm{min})$} \\
\hline & & No stenosis & Stenosis 1 & Stenosis 2 & Stenosis 3 \\
\hline Heart rate (bpm) & $155 \pm 7$ & $202 \pm 10^{*}$ & $195 \pm 9^{*}$ & $201 \pm 7^{*}$ & $197 \pm 8^{*}$ \\
\hline $\begin{array}{l}\text { Left ventricular end-diastolic pressurc } \\
(\mathrm{mm} \mathrm{Hg})\end{array}$ & $8 \pm 1$ & $5 \pm 1$ & $6 \pm 1$ & $7 \pm 1$ & $8 \pm 1 \dagger$ \\
\hline Systolic blood pressure $(\mathrm{mm} \mathrm{Hg})$ & $133 \pm 5$ & $139 \pm 7$ & $135 \pm 6$ & $133 \pm 6$ & $132 \pm 5$ \\
\hline Mean aortic pressure $(\mathrm{mm} \mathrm{Hg})$ & $115 \pm 6$ & $102 \pm 5^{*}$ & $104 \pm 5^{*}$ & $101 \pm 5^{*}$ & $97 \pm 5^{*}$ \\
\hline Peak positive $\mathrm{dP} / \mathrm{dt}(\mathrm{mm} \mathrm{Hg} / \mathrm{sec})$ & $2038 \pm 178$ & $3782 \pm 234^{*}$ & $3794 \pm 215^{*}$ & $3524 \pm 189^{*}$ & $3244 \pm 210^{*}$ \\
\hline Peak negative $\mathrm{dP} / \mathrm{dt}(\mathrm{mm} \mathrm{Hg} / \mathrm{sec})$ & $1961 \pm 108$ & $2267 \pm 123$ & $2279 \pm 87$ & $2389 \pm 164 \S$ & $2142 \pm 122$ \\
\hline
\end{tabular}

$\mathrm{dP} / \mathrm{dt}=$ rate of change of pressure with time; values are mean $\pm \mathrm{SEM}$.

${ }^{*} p<0.001$ vs control; $\dagger p<0.05$ vs no stenosis; $\ddagger p<0.001$ vs no stenosis; $\S p<0.01$ vs control.

Gould et al. ${ }^{1}$ demonstrated that only very severe coronary stenoses cause an impairment of resting coronary blood flow, whereas less severe lesions, within an approximate range of $45 \%$ to $90 \%$ diameter stenosis, show a relatively linear impairment of reactive hyperemia. With more severe lesions, reactive hyperemia is abolished. This concept provides a convenient measure of the potential importance of moderately severe coronary lesions which do not impair resting blood flow or regional function. This range of severity of coronary lesions is perhaps most clinically relevant because patients develop angina during stress, presumably because of exhaustion of flow reserve secondary to lesions which, nevertheless, allow sufficient blood flow to prevent symptoms at rest. Thus, in the evaluation of patients with suspected coronary disease, tests which can detect abnormalities associated with lower grade obstructions are expected to be of greatest use.

Recently, direct measurement of coronary flow reserve $^{2,3}$ has been proposed as an alternative approach to the assessment of the importance of coronary lesions in humans. Many patients have a relative diminution or "subcritical" impairment of flow reserve in contrast to a total abolition of flow reserve. One would expect that lesions associated with these subcritical impairments of coronary flow reserve could be detected under conditions of stress. Traditional methods used to do this include the various forms of exercise stress testing and nonexercise methods to elicit regional heterogeneity of coronary perfusion, wall motion abnormalities, or ECG findings. Thus, while it is interesting to note that the relation between arteriographically defined stenoses and coronary flow reserve measurements in patients is imperfect, ${ }^{4}$ the relation between detected impairments of coronary reserve and evocation of stress-induced abnormalities has not been extensively studied. ${ }^{5.8}$ Such studies would be of relevance in helping to define the utility of the flow reserve index compared to the more traditional exercise and nonexercise methods used by the clinician to assess the functional importance of a coronary lesion. This is underscored by the fact that methods are becoming available that may allow nearly routine measurement of this index in patients. ${ }^{3,9-12}$

Beta-adrenergic agonists improve myocardial contractility but, in the setting of coronary artery stenoses, this effect may also aggravate supplydemand imbalances..$^{13,14}$ As a consequence, these agents have been used both experimentally and clinically to unmask functionally significant coronary stenoses. ${ }^{13-27}$ When isoproterenol has been used in this fashion, regional dysfunction has been shown experimentally only in the setting of very severe coronary stenoses. ${ }^{20}$ The ability to elicit dysfunction in the face of subcritical stenoses, defined on the basis of reductions of flow reserve, has not been studied. As argued previously, tests which can detect abnormalities associated with lower grade obstructions would be of greatest use, thus emphasizing the importance of studying such methods with regard to subcritical coronary lesions. Therefore, the purpose of this experiment was to establish the effects of isoproterenol on regional function in the face of mild, single-vessel coronary stenoses defined on the basis of graded, subcritical impairments of coronary flow reserve.

\section{METHODS}

Definitions. The following definitions of terms will be used for this experiment. A "critical" coronary stenosis is one associated with a flow reserve ratio of one and a concomitant mild impairment of resting coronary blood flow. A "subcritical" coronary stenosis is one associated normal resting blood flow and a coronary flow reserve value of greater than one but less than the value measured in the absence of a stenosis. A "near-critical" stenosis is one with a flow reserve ratio of nearly one. Relative 
Table II. Regional function parameters at rest and during isoproterenol infusions in the presence and absence of coronary stenoses: Part A

\begin{tabular}{|c|c|c|c|c|c|}
\hline & \multirow[b]{2}{*}{ Control } & \multicolumn{4}{|c|}{ Isoproterenol infusion $(0.25 \mu \mathrm{g} / \mathrm{kg} / \mathrm{min})$} \\
\hline & & $\begin{array}{c}\text { No } \\
\text { stenosis }\end{array}$ & $\begin{array}{c}\text { Stenosis } \\
1\end{array}$ & $\begin{array}{c}\text { Stenosis } \\
2\end{array}$ & $\begin{array}{c}\text { Stenosis } \\
3\end{array}$ \\
\hline \multicolumn{6}{|l|}{ Ischemic zone } \\
\hline End-diastolic segment length (mm) & $9.9 \pm 0.4$ & $9.8 \pm 0.5$ & $9.7 \pm 0.5$ & $9.8 \pm 0.5$ & $10.4 \pm 0.5$ \\
\hline End-systolic segment length (mm) & $8.0 \pm 0.4$ & $6.8 \pm 0.5^{*}$ & $6.83 \pm 0.5^{*}$ & $7.1 \pm 0.5 \dagger$ & $8.7 \pm 0.6 \dagger$ \\
\hline Fractional shortening $(\%)$ & $19.7 \pm 2.0$ & $30.9 \pm 3.2 \S$ & $29.4 \pm 3.2 \S$ & $27.3 \pm 3.1^{*}$ & $17.4 \pm 3.3 \ddagger$ \\
\hline Fractional shortening ( $\%$ of control) & - & $160 \pm 11$ & $152 \pm 10$ & $138 \pm 9$ & $74 \pm 15 \ddagger$ \\
\hline \multicolumn{6}{|l|}{ Nonischemic zone } \\
\hline End-diastolic segment length (mm) & $10.4 \pm 0.8$ & $9.7 \pm 0.7^{*}$ & $9.7 \pm 0.7^{*}$ & $9.8 \pm 0.7^{*}$ & $10.3 \pm 0.7 \|$ \\
\hline End-systolic segment length (mm) & $9.1 \pm 0.7$ & $7.9 \pm 0.5 \S$ & $7.9 \pm 0.5 \S$ & $7.8 \pm 0.4 \S$ & $8.0 \pm 0.4 \S$ \\
\hline Fractional shortening $(\%)$ & $12.7 \pm 1.6$ & $19.1 \pm 1.3 \S$ & $18.2 \pm 1.9^{*}$ & $20.0 \pm 2.3 \S$ & $21.6 \pm 2.1 \S$ \\
\hline Fractional shortening ( $\%$ of control) & - & $185 \pm 38$ & $183 \pm 57$ & $202 \pm 55$ & $197 \pm 38$ \\
\hline
\end{tabular}

Values are mean \pm SEM.

${ }^{*} p<0.01$ vs control; $\uparrow p<0.05$ vs control; $\ddagger p<0.001$ vs no stenosis; $\$ p<0.001$ vs control; $\| p<0.05$ vs no stenosis.

coronary flow is flow divided by flow during a resting, control state in the absence of isoproterenol infusion.

Animal preparation. Twenty-three mongrel dogs of either sex (average weight $24.6 \mathrm{~kg}$, range 22.7 to 35.7 ) were anesthetized with intravenous pentobarbital sodium (35 $\mathrm{mg} / \mathrm{kg}$ ) and ventilated with room air by means of a Harvard respirator. A left thoracotomy was performed in the fifth intercostal space. The left anterior descending or the circumflex coronary artery was dissected free for a length of 1 to $2 \mathrm{~cm}$ and instrumented with a snare occluder, a hard plastic screw occluder, or a rubber cuff occluder (R. E. Jones, Silver Spring, Md.) and an appropriately sized electromagnetic flow probe (Carolina Medical Electronics, Inc., King, North Carolina). All flow probes were calibrated by means of timed collections of blood of known hematocrit infused at physiologic blood How rates. Two pairs of subendocardial ultrasonic quartz crystals were implanted in the midequatorial region of the left ventricle and approximately parallel to the circumferential plane. One pair was implanted in the left anterior descending coronary artery distribution distal to the occluder and in the central area of the zone rendered dyskinetic and cyanotic during coronary occlusion (ischemic zone), and one pair was implanted in the left circumflex coronary artery region (nonischemic zone). In four studies the circumflex bed was used as the ischemic 2one. The crystals were connected to a Sonomicrometer 120 (Triton Technology, San Diego, Calif.). Proper crystal alignment was confirmed in three ways: by oscilloscopic display of the sonomicrometer signals (Tektronix, Inc., Beaverton, Ore., model 2213A) during the experiment, by ensuring that total coronary occlusion elicited prompt dyskinetic regional function, and by dissection and direct inspection of the crystal position after the study. All crystals were within the inner one third of the myocardial wall, but misalignment was noted in five experiments which were excluded from data analysis. A $5 F$ highfidelity micromanometer (Millar Instruments, Inc., Hous- ton, Tex) was inserted through a stab wound into the apex of the left ventricle for measurement of left ventricular pressure and its first derivative (dP/dt). A second $5 \mathrm{~F}$ high-fidelity micromanometer was passed into the ascending aorta through a carotid arteriotomy.

Experimental protocol. Heart rate, rate of left ventricular pressure change with time $(\mathrm{dP} / \mathrm{dt})$, left ventricular pressure, mean aortic pressure, subendocardial segment lengths for the left anterior descending and circumflex regions, and phasic and mean coronary blood flow were recorded continuously on a Gould $2800 \mathrm{~S}$ recorder.

The experiment was undertaken in two parts. In part A the severity of the stenoses was characterized only by the relative changes in coronary blood flow induced during a 3 - to 5-minute steady-state infusion of isoproterenol $\mathbf{0 . 2 5}$ $\mu \mathrm{g} / \mathrm{kg} / \mathrm{min}$ ). Observations were made during the control state and during isoproterenol infusion in the absence of a stenosis. Three levels of coronary stenosis were achieved by progressive coronary occlusion with a rubber cuff occluder during the isoproterenol infusion. The goal was to study impairment of coronary blood flow with a mild stenosis (stenosis No. 1) that decreased blood flow to a level midway between resting and maximal flow seen during infusion in the absence of a stenosis, a more severe stenosis (stenosis No. 2) that limited flow to resting levels during the infusion, and a very severe stenosis (stenosis No. 3) that reduced blood flow to approximately one half of the resting flow. Complete recovery was allowed between tests of each stenosis so that hemodynamic segment length and coronary blood flow measurements had returned to control levels. The absolute level of coronary blood flow rose minimally above control levels in response to isoproterenol in some dogs, possibly because of a decrease in aortic perfusion pressure, and this precluded a full complement of observations at the desired relative blood flow levels described above. These dogs were excluded from data analysis leaving nine dogs with a full complement of observations. 
Table III. Coronary flow parameters of the ischemic zone at rest and during isoproterenol infusion in the presence and absence of coronary stenoses: Part A

\begin{tabular}{lccccc}
\hline & & \multicolumn{3}{c}{ Isoproterenol infusion $(0.25 \mu \mathrm{g} / \mathrm{kg} / \mathrm{min})$} \\
\cline { 3 - 6 } & Control & stenosis & Stenosis & Stenosis & Stenosis \\
& & 1 & 2 & 3 \\
\hline Coronary blood flow (ml/min) & $36.1 \pm 5.0$ & $53.8 \pm 7.6^{*}$ & $48.3 \pm 6.6 \dagger$ & $32.0 \pm 4.8 \ddagger$ & $16.8 \pm 3.2^{*} \ddagger$ \\
Coronary blood flow $(\%$ control) & - & $153 \pm 12$ & $136 \pm 7$ & $89 \pm 4 \ddagger$ & $49 \pm 3 \ddagger$ \\
\hline
\end{tabular}

Values are mean $\pm \mathrm{SEM}$.

${ }^{*} p<0.001$ vs control; $\nmid p<0.01$ vs control; $\ddagger p<0.001$ vs no stenosis.

In part B, the severity of the stenoses was quantitated by the impairment of resting coronary flow reserve. Coronary flow reserve was determined at rest in the absence of a stenosis by the ratio of peak blood flow after a 20-second total occlusion to resting coronary blood flow. Isoproterenol was then infused for 3 to 5 minutes in the absence of a stenosis. After full recovery, isoproterenol was again infused, and a rigid, plastic screw occluder was then tightened slightly. After 3 to 5 minutes of infusion, full recovery was allowed and coronary flow reserve at rest was reassessed before any alteration of the occluder was made. This sequence was repeated in random order to create five different stenoses that impaired coronary flow reserve but did not impair resting coronary blood flow. The stenoses created within each dog were reassigned on the basis of the degree of impairment of coronary flow reserve. The mildest impairment was considered stenosis No. 1 and the maximal impairment was considered stenosis No. 5. This allowed creation of five stenotic groups containing one observation from each dog with statistically significant differences in the degree of coronary flow reserve impairment (see below). It should be emphasized that collapse or expansion of the screw occluder could not occur between the resting and infusion phases of the protocol. In addition, stenoses that impaired resting coronary blood flow were excluded from analysis to constrain observations in the subcritical range. A full complement of observations was achieved in nine dogs.

Data analysis. End-diastolic segment lengths and left ventricular end-diastolic pressures were determined at the beginning of left ventricular contraction when the $\mathrm{dP} / \mathrm{dt}$ became positive. End-systolic segment lengths were determined at peak negative $\mathrm{dP} / \mathrm{dt} .{ }^{28}$ Percentage of systolic shortening was determined by calculating the ratio of end-diastolic segment length minus end-systolic segment length to end-diastolic segment length multiplied by 100 . All measurements were obtained by averaging data from three to five normally conducted beats. These were made at rest and during isoproterenol infusion in the absence of a stenosis and for each new level of coronary stenosis.

The coronary flow reserve was expressed both as the simple ratio and as a percentage of the maximal coronary flow reserve obtained in the absence of a coronary stenosis. The percentage of maximal coronary flow reserve was determined by: $(\mathrm{CFR}-1) /\left(\mathrm{CFR}_{\max }-1\right) \times 100 \%$, where
CFR = measured coronary flow reserve associated with any lesion and $\mathrm{CFR}_{\max }=$ the maximal coronary flow reserve in the absence of a coronary stenosis. 6,7

Statietical analysis. Data for all parameters were analyzed by means of repeated-measures analysis of variance. When overall sigificance was detected, a Bonferroni test was used to determine which stenosis stages differed from the resting control stage and/or the nonstenosis infusion stage. ${ }^{29}$ Data analysis for part $B$ also incorporated the use of paired $t$ tests to determine if there was a significant difference between coronary blood flow at rest and during infusion for each stenosis level. Tukey's test was used to assess differences among reactive hyperemia values associated with each stenosis. ${ }^{29}$ Correlations were perfomed by linear, logarithmic, and polynomial regression analysis. Data are reported as mean \pm standard error of the mean (SEM). Findings were considered significant when $p<0.05$.

\section{RESULTS}

Part A. Table I summarizes the hemodynamic effects of isoproterenol during the five stages of the protocol. The expected increases in heart rate and peak positive $\mathrm{dP} / \mathrm{dt}$ and decrease in mean aortic pressure were noted during isoproterenol infusion. Table II summarizes the regional segment shortening data. The fractional shortening results showed an increase with isoproterenol from $19.7 \pm 2.0 \%$ to $30.9 \pm 3.2 \%(p<0.001)$ in the absence of a stenosis. Regional function fell progressively, but not significantly, to $29.4 \pm 3.2 \%$ and $27.3 \pm 3.1 \%$ for stenoses Nos. 1 and 2, respectively, and then to $17.4 \pm 3.3 \%$ for stenosis No. 3 ( $p<0.001$ vs no stenosis).

The coronary blood flow (Table III) at rest was $36.1 \pm 5.0 \mathrm{cc} / \mathrm{min}$ and rose to $53.8 \pm 7.6 \mathrm{cc} / \mathrm{min}$ in the absence of a stenosis $(p<0.001)$. With stenosis No. 1, coronary flow was greater than control values $(48.3 \pm 6.6 \mathrm{cc} / \mathrm{min}, p<0.01)$ but not significantly less than during isoproterenol infusion without a stenosis. With stenosis No. 2, flow was not different from control levels ( $32.0 \pm 4.8 \mathrm{ml} / \mathrm{min}, p=\mathrm{NS})$ but was decreased relative to the nonstenotic state $(p<0.001)$. Coronary flow with the most severe 


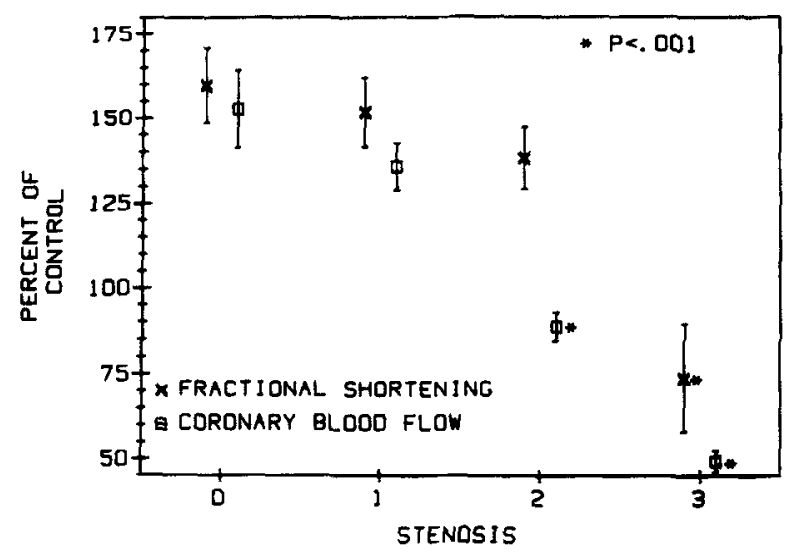

Fig. 1. Fractional shortening and coronary blood flow are shown for part $A$ of the experimental protocol in the absence of stenosis and during three progressively severe stenoses. ${ }^{*} p<0.001$ vs nonstenotic control state. Values are mean $\pm \mathrm{SEM} ; \mathrm{n}=9$.

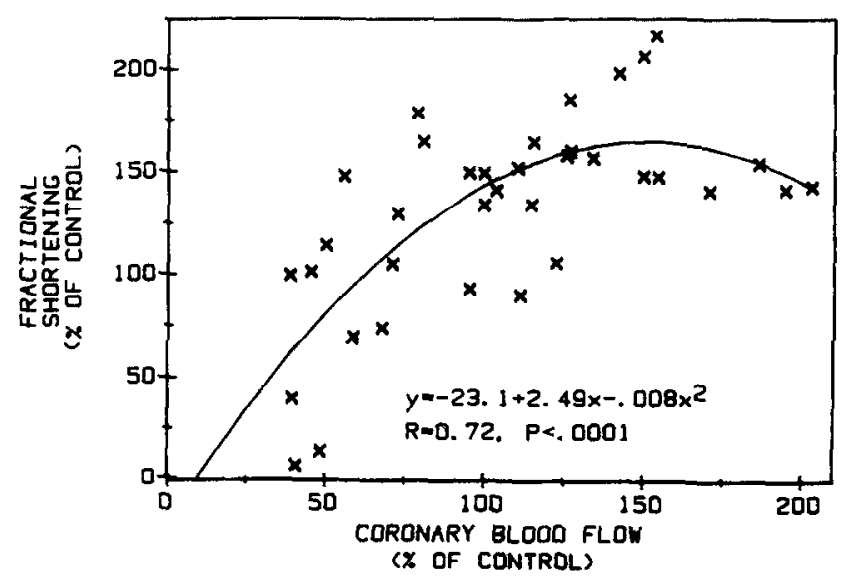

Fig. 2. Relation between coronary blood flow and fractional shortening is shown. Symbols represent individual observations from nine dogs in part $A$.

Table IV. Hemodynamics at rest and during isoproterenol infusions in the presence and absence of coronary stenoses: Part B

\begin{tabular}{|c|c|c|c|c|c|c|c|}
\hline & \multirow[b]{2}{*}{ Control. } & \multicolumn{6}{|c|}{ Isoproterenol infusion $(0.25 \mu \mathrm{g} / \mathrm{kg} / \mathrm{min})$} \\
\hline & & $\begin{array}{c}\text { No } \\
\text { stenosis }\end{array}$ & $\begin{array}{c}\text { Stenosis } \\
1\end{array}$ & $\begin{array}{l}\text { Stenosis } \\
2\end{array}$ & $\begin{array}{c}\text { Stenosis } \\
3\end{array}$ & $\begin{array}{c}\text { Stenosis } \\
4\end{array}$ & $\begin{array}{l}\text { Stenosis } \\
\quad 5\end{array}$ \\
\hline Heart rate $(\mathrm{bpm})$ & $150 \pm 8$ & $192 \pm 10^{*}$ & $187 \pm 8^{*}$ & $187 \pm 8^{*}$ & $187 \pm 7^{*}$ & $191 \pm 7^{*}$ & $191 \pm 9^{*}$ \\
\hline $\begin{array}{l}\text { Left ventricular end-diastolic } \\
\text { pressure }(\mathrm{mm} \mathrm{Hg})\end{array}$ & $8 \pm 1$ & $6 \pm 1 \dagger$ & $6 \pm 1$ & $7 \pm 1$ & $7 \pm 1$ & $6 \pm 1$ & $7 \pm 1$ \\
\hline $\begin{array}{l}\text { Systolic blood pressure } \\
\text { (mm Hg) }\end{array}$ & $133 \pm 5$ & $142 \pm 6$ & $136 \pm 6$ & $137 \pm 5$ & $138 \pm 5$ & $138 \pm 6$ & $136 \pm 4$ \\
\hline $\begin{array}{l}\text { Mean aortic pressure } \\
(\mathrm{mm} \mathrm{Hg})\end{array}$ & $115 \pm 6$ & $103 \pm 5 \ddagger$ & $102 \pm 4^{*}$ & $101 \pm 3^{*}$ & $103 \pm 4 \ddagger$ & $106 \pm 5$ & $103 \pm 5 \ddagger$ \\
\hline $\begin{array}{l}\text { Peak positive } \mathrm{dP} / \mathrm{dt} \\
\text { (mm } \mathrm{Hg} / \mathrm{sec})\end{array}$ & $2042 \pm 177$ & $3756 \pm 239^{*}$ & $3737 \pm 243^{*}$ & $3814 \pm 189^{*}$ & $3750 \pm 208^{*}$ & $3713 \pm 206^{*}$ & $3474 \pm 166^{*}$ \\
\hline $\begin{array}{l}\text { Peak negative dP/dt } \\
\text { (mm Hg/sec) }\end{array}$ & $1917 \pm 124$ & $2210 \pm 150$ & $2178 \pm 129$ & $2113 \pm 95$ & $2223 \pm 199$ & $2177 \pm 120$ & $2202 \pm 136$ \\
\hline
\end{tabular}

Values are mean $\pm \mathrm{SEM}$.

${ }^{*} p<0.001$ vs control; $\dagger p<0.05$ vs control; $\ddagger p<0.01$ vs control.

stenosis was significantly reduced to $16.8 \pm 3.2 \mathrm{cc} /$ min compared to both the resting control state and during isoproterenol infusion in the nonstenotic state.

Figs. 1 and 2 demonstrate the relation between regional shortening and coronary blood flow for part A. This relation was best described by a curvilinear polynomial function, $y=-23.1+2.94 x-0.008 x^{2}$; $r=0.72, p<0.0001$, where $\mathrm{y}$ is fractional shortening and $\mathbf{x}$ is blood flow, both expressed as a percentage of control values. This curve fit was superior to either linear or logarithmic fits within the range of observations made. Extrapolation beyond this range into higher flow ranges would predict a decrease in regional function, which is clearly not physiologic.
Thus, the interpretation of the data within the observed range is that there is a relatively flat relation between flow and function in the high flow ranges and a more linear fall below $100 \%$ of control flows.

Part B. Table IV summarizes the hemodynamic responses to isoproterenol infusion in the presence and absence of coronary stenoses that impaired reactive hyperemia but not resting coronary blood flow. Comparable degrees of tachycardia, decrease in mean blood pressure, and increase in peak positive rate of change of left ventricular pressure $(\mathrm{dP} / \mathrm{dt})$ were induced by isoproterenol in the presence and absence of coronary stenoses.

Table V summarizes the blood flow and coronary 
Table $\mathrm{V}$. Coronary flow parameters of the ischemic zone at rest and during isoproterenol infusions in the presence and absence of coronary stenoses: Part $B$

\begin{tabular}{|c|c|c|c|c|c|c|}
\hline & $\begin{array}{c}\text { No } \\
\text { stenosis }\end{array}$ & $\begin{array}{c}\text { Stenosis } \\
1\end{array}$ & $\begin{array}{c}\text { Stenosis } \\
2\end{array}$ & $\begin{array}{c}\text { Stenosis } \\
3\end{array}$ & $\begin{array}{c}\text { Stenosis } \\
4\end{array}$ & $\begin{array}{c}\text { Stenosis } \\
5\end{array}$ \\
\hline \multicolumn{7}{|c|}{ Coronary flow reserve } \\
\hline Rest & $3.70 \pm 0.26$ & $2.84 \pm 0.21^{*}$ & $2.53 \pm 0.16^{*}$ & $2.01 \pm 0.12^{*}$ & $1.63 \pm 0.11^{*}$ & $1.11 \pm 0.05^{*}$ \\
\hline$\%$ of control & - & $68.2 \pm 5.1$ & $56.8 \pm 4.1$ & $39.2 \pm 4.5$ & $23.6 \pm 4.5$ & $4.1 \pm 1.9$ \\
\hline \multicolumn{7}{|c|}{ Coronary blood flow (ml/min) } \\
\hline Rest & $41.7 \pm 4.1$ & $41.7 \pm 4.9$ & $40.5 \pm 4.3$ & $40.6 \pm 4.8$ & $40.9 \pm 5.5$ & $38.2 \pm 4.1$ \\
\hline Isoproterenol & $58.6 \pm 7.6 \dagger$ & $56.9 \pm 8.5 \dagger$ & $54.8 \pm 7.4 \dagger$ & $50.2 \pm 6.6 \dagger$ & $50.2 \pm 7.7 \dagger$ & $34.3 \pm 4.9^{*}$ \\
\hline$\%$ of control & $148 \pm 10$ & $141 \pm 10$ & $135 \pm 7$ & $126 \pm 8$ & $123 \pm 10$ & $85 \pm 3^{*}$ \\
\hline
\end{tabular}

Values are mean \pm SEM.

${ }^{*} p<0.001$ vs no stenosis; $\dagger p<0.01$ vs rest; coronary flow reserve values, expressed as percentage of control, all differ from each other at the $p<0.01$ level except for stenosis 1 and 2, which are different at the $p<0.05$ level (Tukey's test, see text).

Table VI. Regional function parameters at rest and during isoproterenol infusions in the presence and absence of coronary stenoses: Part B

\begin{tabular}{|c|c|c|c|c|c|c|c|}
\hline & \multirow[b]{2}{*}{ Control } & \multirow[b]{2}{*}{$\begin{array}{c}\text { No } \\
\text { stenoses }\end{array}$} & \multicolumn{5}{|c|}{ Isoproterenol infusion $(0.25 \mu \mathrm{g} / \mathrm{kg} / \mathrm{min})$} \\
\hline & & & $\begin{array}{c}\text { Stenosis } \\
1\end{array}$ & $\begin{array}{l}\text { Stenosis } \\
2\end{array}$ & $\begin{array}{c}\text { Stenosis } \\
3\end{array}$ & $\begin{array}{c}\text { Stenosis } \\
4\end{array}$ & $\begin{array}{l}\text { Stenosis } \\
\quad 5\end{array}$ \\
\hline \multicolumn{8}{|l|}{ Ischemic zone } \\
\hline $\begin{array}{l}\text { End-diastolic segment } \\
\text { length }(\mathrm{mm})\end{array}$ & $9.9 \pm 0.4$ & $9.6 \pm 0.5$ & $9.5 \pm 0.6$ & $9.6 \pm 0.5$ & $9.6 \pm 0.5$ & $9.5 \pm 0.6$ & $9.7 \pm 0.6$ \\
\hline $\begin{array}{l}\text { End-systolic segment } \\
\text { length (mm) }\end{array}$ & $7.9 \pm 0.5$ & $6.5 \pm 0.6^{*}$ & $6.6 \pm 0.6^{*}$ & $6.7 \pm 0.6^{*}$ & $6.7 \pm 0.6^{*}$ & $6.6 \pm 0.6^{*}$ & $7.1 \pm 0.6^{*}$ \\
\hline $\begin{array}{l}\text { Fractional shortening } \\
(\%)\end{array}$ & $20.3 \pm 2.3$ & $32.6 \pm 3.9^{*}$ & $31.0 \pm 3.6^{*}$ & $31.0 \pm 3.7^{*}$ & $30.6 \pm 3.6^{*}$ & $30.6 \pm 3.6^{*}$ & $27.5 \pm 3.4^{*}$ \\
\hline $\begin{array}{l}\text { Fractional shortening } \\
\text { (\% of control) }\end{array}$ & - & $162 \pm 12$ & $155 \pm 11$ & $155 \pm 11$ & $152 \pm 10$ & $153 \pm 11$ & $136 \pm 10 \ddagger$ \\
\hline \multicolumn{8}{|l|}{ Nonischemic zone } \\
\hline $\begin{array}{l}\text { End-diastolic segment } \\
\text { length }(\mathrm{mm})\end{array}$ & $10.1 \pm 0.8$ & $9.4 \pm 0.7^{*}$ & $9.4 \pm 0.7^{*}$ & $9.6 \pm 0.7$ & $9.4 \pm 0.7^{*}$ & $9.4 \pm 0.7^{*}$ & $9.5 \pm 0.7 \S$ \\
\hline $\begin{array}{l}\text { End-systolic segment } \\
\text { length (mm) }\end{array}$ & $8.7 \pm 0.7$ & $7.4 \pm 0.6^{*}$ & $7.4 \pm 0.6^{*}$ & $7.4 \pm 0.6^{*}$ & $7.4 \pm 0.5^{*}$ & $7.4 \pm 0.5^{*}$ & $7.3 \pm 0.5^{*}$ \\
\hline $\begin{array}{l}\text { Fractional shortening } \\
(\%)\end{array}$ & $13.9 \pm 0.9$ & $21.2 \pm 2.3^{*}$ & $20.9 \pm 2.8^{*}$ & $21.8 \pm 2.9^{*}$ & $21.0 \pm 2.9^{*}$ & $21.2 \pm 2.9^{*}$ & $22.2 \pm 3.1^{*}$ \\
\hline $\begin{array}{l}\text { Fractional shortening } \\
\text { (\% of control) }\end{array}$ & - & $167 \pm 17$ & $164 \pm 22$ & $173 \pm 26$ & $158 \pm 16$ & $165 \pm 23$ & $175 \pm 26$ \\
\hline
\end{tabular}

Values are mean \pm SEM.

${ }^{*} p<0.001$ vs control; $\nmid p<0.01$ vs no stenosis; $\ddagger p<0.001$ vs no stenosis; $\S p<0.01$ vs control.

flow reserve results. Coronary flow reserve at rest was $3.70 \pm 0.26$, and each stenosis showed a progressive impairment of this parameter. For stenosis No. 5 coronary flow reserve was $1.11 \pm 0.05$ or $4.1 \pm$ $1.9 \%$ of control values signifying near-total loss of reactive hyperemia. Resting coronary blood flow was stable throughout the protocol.

Table VI summarizes the regional function results at control levels and during isoproterenol infusion. Shortening increased in the absence of a stenosis from $20.3 \pm 2.3$ to $32.6 \pm 3.9 \% \quad(p<0.001)$. For stenoses Nos. 1 to 4 , the shortening remained at this elevated level. With stenosis No. 5, shortening was significantly lower $(27.5 \pm 3.4 \%)$ than during infusion in the absence of a stenosis $(p<0.01)$ but was still greater than the resting control shortening $(p<0.001)$.

From Table V, it is evident that the degree of hyperemia induced by isoproterenol was less than that produced by the brief coronary occlusion at rest for each stenosis group except stenosis No. 5. For this last group, flow was not significantly different from the resting control flow as predicated by the experimental design. Regional dysfunction was noted only in the latter group. Moreover, the degree of hyperemia during isoproterenol infusion was rela- 


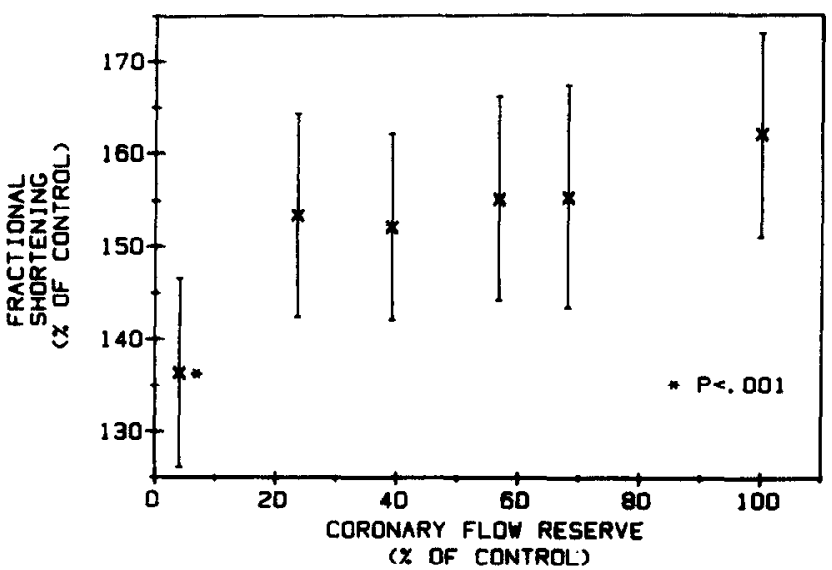

Fig. 3. Relation between coronary flow reserve and fractional shortening during isoproterenol infusion is shown (part B). Significant deterioration occurred only in the face of near absence of coronary flow reserve. Values are mean $\pm \mathrm{SEM} ; \mathrm{n}=9 .{ }^{*} p<0.001$ vs nonstenotic control state.

tively similar for stenoses Nos. 1 to 4 . This is in keeping with a rather constant metabolic demand induced by the isoproterenol, which did not exhaust vasodilator reserve until stenosis No. 5 , even though flow reserve as assessed by the more maximal stimulus of coronary occlusion at rest clearly unveiled the potential functional impairment of flow within each stenosis group.

Fig. 3 demonstrates the relation between regional function during isoproterenol infusion and resting coronary flow reserve. Regional function showed significant deterioration relative to the nonstenotic state only when coronary flow reserve was virtually absent. Note, however, that this level of regional shortening was still above resting control values.

\section{DISCUSSION}

The results of this experiment demonstrate that, in the presence of near-critical coronary stenoses, isoproterenol can elicit relative regional dysfunction, but that with less severe impairments of coronary flow reserve, regional function is maintained relative to resting control values. Moreover, despite impairments of the maximal increase in postocclusion coronary flow, the stress of the isoproterenol infusion failed to exhaust vasodilator reserve except with the most severe stenoses. This suggests that the clinical use of this drug to elicit regional dysfunction will not be sensitive in detecting patients with mild or moderate lesions.

Cllnical studles. Several clinical investigations of the effects of isoproterenol have been reported. Krasnow et al. ${ }^{21}$ studied a heterogeneous group of patients, including coronary patients, and noted angina induction in only two subjects. Coronary flow increased by $72 \%$ and only one patient demonstrated actual reversal of arteriovenous lactate differences in coronary sinus samples. Cohen et al. ${ }^{22}$ extended these observations in a group of patients with a broad range of angiographically documented coronary diseases. By means of indicator dilution methods, they showed that isoproterenol caused remarkably similar increases in coronary flow in both normal subjects and in coronary patients, whereas analysis of lactate metabolism demonstrated clear abnormalities in the majority of coronary subjects. Wexler et al. ${ }^{23}$ showed that isoproterenol infusion caused no ECG abnormalities in normal subjects, whereas ST segment and $T$ wave abnormalities were commonly induced in patients with prior myocardial infarction. However, no chest pain was induced in this study. Combs and Martin ${ }^{24}$ performed a similar study in 20 patients with more than a $50 \%$ diameter reduction of a major coronary branch and in 15 patients judged to have normal coronary arteries. Twelve of $20(60 \%)$ coronary patients manifested abnormal ECG findings during the infusion. Manca et al. ${ }^{25}$ used the presence of at least one $75 \%$ stenosis on the cineangiogram to designate the presence of significant coronary disease and found a $70 \%$ sensitivity for detection of these patients when isoproterenol-induced ECG abnormalities were present. Horowitz et al. ${ }^{26}$ used direct coronary injections of $\mathrm{Xe}^{133}$ to estimate coronary flow response to isoproterenol. In contrast to the study of Cohen et al., ${ }^{22}$ these investigators found that nearly all patients increased coronary flow, but this hyperemic response was markedly attenuated in patients with angiographically defined stenoses of at least $70 \%$ diameter reduction. Only one patient developed chest pain. Similarly, Horowitz et al. ${ }^{27}$ noted a general but highly variable decrement in isoproterenol-induced hyperemia in relation to angiographic severity of coronary lesions and presence or absence of collaterals. These prior clinical investigations are limited in several ways with respect to the objectives of this current study. First, there was a marked heterogeneity in patient groups, which frequently included patients with total obstructions or prior infarctions and resting wall motion abnormalities. Second, it is difficult to determine from historic or angiographic data which patients had subcritical or critical coronary lesions ${ }^{4}$ and, therefore, the studies do not allow conclusions as to how useful the technique is in identifying patients with mild disease. Third, no assessment of regional function during the isoproterenol stress was undertaken. And, finally, none gives information regarding resting coronary flow reserve as a means of identifying the severity of coronary lesions. 
Experimental studies. Several animal investigations are important to consider. Daniell et al..$^{15}$ studied the effects of injections of isoproterenol on coronary blood flow and myocardial function in dogs. They described a triphasic response of coronary blood flow characterized by an initial rise, a sharp drop caused by decreased coronary perfusion pressure, and then a sustained rise in blood flow as perfusion pressure rose slightly and then stabilized. They showed that ventricular force generation, as measured by a strain gauge, largely paralleled this pattern of coronary flow. Moreover, during the phase when coronary flow fell to control levels, ventricular force generation remained at or above preisoproterenol levels despite evidence of anaerobic metabolism.

Griggs et al. ${ }^{16}$ determined that the epicardial and endocardial lactate/pyruvate ratios were similar during control and isoproterenol-stimulated states in the absence of coronary stenoses. In contrast, subendocardial lactate/pyruvate ratios rose with partial constriction of left main coronary artery flow during isoproterenol infusion. The constriction did not impair basal coronary flow, but flow during the infusion rose by only $61 \%$ compared to a $115 \%$ increase in the absence of a stenosis. Although this demonstrated a relative supply-demand imbalance in the subendocardium, neither regional function nor resting coronary flow reserve was documented.

Buckberg and Ross ${ }^{17}$ demonstrated that very high doses of isoproterenol could induce relative underperfusion of the subendocardium even in the absence of coronary stenoses. Epicardial coronary flow, subendocardial/epicardial flow ratios, and coronary perfusion pressure paralleled the observed regional contractile function as measured by strain gauges. Thus, initial increases in flow and function were followed at higher doses of isoproterenol by a progressive decrease in each parameter but of note is that contractile function always remained above control levels despite relative underperfusion of the subendocardium.

Vatner et $\mathrm{al}^{30,31}$ studied the effects of isoproterenol on normal and ischemic myocardium in conscious dogs. The ischemic model in one study ${ }^{29}$ consisted of left main coronary artery constriction resulting in global ischemia with an average $30 \%$ decrease in epicardial coronary blood flow, significant cardiac enlargement, and deterioration of velocity of fiber shortening. In this severely ischemic model, administration of isoproterenol caused additional deterioration of ventricular function. In another study, ${ }^{31}$ the effects of isoproterenol in the presence of only regional ischemia were determined. In contrast to the prior investigation, isoproterenol improved overall left ventricular function. More important, despite deterioration of function in severely ischemic segments with isoproterenol, all moderately ischemic zones and most "border zone" segments showed improvement in function despite preinfusion coronary flows of approximately $65 \%$ and $90 \%$ of control values, respectively. Furthermore, despite a depressed velocity of postocclusion shortening, an increase in function was noted during isoproterenol infusion that paralleled a rise in blood flow to these regions. The return of function exceeded preocclusion levels in the border zone and approximated preocclusion levels in the moderately ischemic zone. In contrast, in the central severely ischemic zone, function showed further deterioration when there was no associated increase in coronary flow. The authors concluded that a strong inotropic agent can improve regional function, even in the ischemic myocardium, as long as additional blood flow can be provided through either primary or collateral channels.

Battler et al. ${ }^{19}$ proposed that isoproterenol could be used to detect "latent" coronary stenoses by evocation of regional dysfunction and ECG abnormalities. Stenoses were created by inflating a hydraulic occluder until mild reduction of systolic wall thickening occurred and deflating it slightly until wall function returned to normal. By means of very small doses of isoproterenol, marked regional dysfunction and ECG abnormalities were demonstrated. These findings are surprising considering the references cited previously, and several factors may have contributed to these dramatic results. First, information regarding coronary flow was not provided in this study and, thus, it is unknown if impairment of resting flow was present. Second, the infusion may have caused a large decrease in both coronary perfusion pressure and coronary flow. ${ }^{15,17}$ Finally, the hydraulic occluder may have partially collapsed, increasing the severity of stenosis and further aggravating a decrease in coronary blood flow. ${ }^{32,33}$ Thus, in the absence of hemodynamic and blood flow data, it is unclear if these stenoses were truly "latent" or comparable to the subcritical stenoses studied in the current investigation.

Gallagher et al. ${ }^{20}$ extended these observations by means of two levels of coronary stenoses created in a similar way. They demonstrated that regional function deteriorated below what was observed both at rest and during isoproterenol infusion in the absence of a stenosis. This occurred despite maintenance of mean transmural myocardial blood flow (microsphere technique) at resting levels. The mildest stenosis was characterized by preservation of some epicardial flow reserve and abolition of midmyocar- 
dial and subendocardial flow reserve during isoproterenol stimulation. The more severe stenosis showed additional loss of subepicardial flow reserve during isoproterenol infusion. Several important differences between that study and the current investigation deserve emphasis. First, the effects of the stenosis on epicardial coronary blood flow and coronary flow reserve were not assessed. Second, although regional function was not impaired at rest, some embarrassment of basal epicardial coronary flow may have been present if one considers the curvilinear relation between epicardial flow and regional function, ${ }^{34}$ This might not be detected by the microsphere technique which assesses both direct and indirect (collateral) flow. Third, the finding that coronary flow during infusion was equal to instead of greater than resting coronary flow suggests that the stenoses might have been associated with a restriction of resting epicardial flow. ${ }^{13-19,21,22,26,30-33}$ Moreover, maintenance of subepicardial reserve with coronary stenoses characterized by mild but significant reductions of basal epicardial coronary flow has been previously documented..$^{35}$ This is also implied by the work of Gould et al., ${ }^{36}$ who demonstrated that flow reserve is not totally abolished until resting epicardial flow has decreased. Finally, several investigators ${ }^{37.39}$ have demonstrated that epicardial flow measurements are generally lower than measures of transmural myocardial blood flow under conditions of vasodilation, and this is probably secondary to enhanced epicardial collateral blood flow. Thus, it is likely that the two "latent" stenoses in the study of Gallagher et al.$^{20}$ were much more severe than the most severe "subcritical" stenosis (stenosis no. 5, part B) in this current study. The current study, therefore, concentrates on observations about the potential effects of isoproterenol in a range of mild coronary stenoses that has not been previously studied.

Another important difference is that isoproterenol caused a substantial enhancement of regional shortening in the current study in both the nonischemic bed and in the ischemic zone prior to creation of a stenosis, whereas this was not the case in the study of Gallagher et al..$^{20}$ The reasons for this disparity are unclear but may be related to the small sample size in their study. Other investigators, however, have documented increased regional function in response to isoproterenol even in ischemic states. ${ }^{31}$ Although dysfunction relative to the nonstenotic group could be detected in the current study, dysfunction below preisoproterenol control levels did not occur. These findings are also in keeping with the observations of Vatner et al..$^{31}$ and others $^{15-17}$ and are emphasized by the results shown in Fig. 2, which demonstrate that a fall of function below resting levels was not seen until significant impairments of relative coronary flow were induced.

Prior work from this laboratory has demonstrated that the relation between subcritical impairments of coronary flow reserve and regional dysfunction during stress is altered by the form of stress utilized., .,7 $^{2}$ This relation, in turn, is predominantly influenced by the determinants of coronary blood flow during the stress itself. Rapid atrial pacing, in the setting of subcritical stenoses, reduced regional function below control levels when coronary flow reserve was approximately two or less, whereas no dysfunction was noted when dopamine infusion was investigated. ${ }^{6,7}$ Thus, the results of the current investigation are intermediate to those two studies. Moreover, these studies begin to determine the lower limits of flow reserve that may impact upon regional function during stress. Such relationships are important in defining the significance of coronary flow reserve measurements at rest relative to the more traditional indicators of the functional significance of coronary disease during stress testing. It is clear that not all impairments of coronary flow reserve are associated with stress-induced regional dysfunction, although metabolic abnormalities, not measured in this study, may well be present under these circumstances as has been previously shown. ${ }^{13-}$ 16, 21,22 These factors must be taken into account particularly as methods for detecting mild impairments of coronary flow reserve in patients become more available. ${ }^{2,3,8-12}$ Furthermore, the results of this and prior studies suggest that the primary determinant of these relationships is the blood flow during the stress itself.

Limitations. Several limitations of the current investigation should be considered. Rigid intraluminal stenoses were not used, but care was taken to circumvent potential changes in stenosis severity between the rest and infusion stages with a rigid screw occluder. Transmural myocardial blood flow was not measured because the study was intended to provide data analogous to the clinical assessment of epicardial coronary tlow reserve and because all of the stenoses (except the most severe stenosis in part A) were associated with conditions of normal or high epicardial flow when collateral flow would not be expected to be of primary importance. While measurement of subendocardial regional function does provide a good index of the relative adequacy of total subendocardial perfusion, ${ }^{40}$ the paucity of 
regional dysfunction seen in this study prevents exclusion of some role of collateral flow in the maintenance of regional function despite impairments of coronary flow reserve. This potential problem was likely to be minimal in the acute model in contrast to chronic models of coronary stenosis, which regularly develop large coronary collaterals. The issue, however, does underscore one of the potential limitations of the clinical use of the coronary flow reserve index measured at rest as an adequate, isolated measure of the "functional" significance of coronary stenoses because the determinants of hyperemic coronary perfusion (epicardial and collateral) are quite different during stress compared to resting conditions and may impact dramatically on the ability to detect abnormalities of parameters that reflect functional derangements. These limitations would apply to both single-vessel coronary disease, as modeled in this investigation, and multivessel disease where collateral recruitment under stress may be quite variable. Finally, it is important to establish the adequacy of the stress induced by isoproterenol. The dose used in this study $(0.25 \mu \mathrm{g} / \mathrm{kg} / \mathrm{min})$ was similar to that used by Gallagher et al. ${ }^{20}(0.2 \mu \mathrm{g} / \mathrm{kg} / \mathrm{min})$ slightly less than that used by Vatner et $\mathrm{al} .^{31}(0.4 \mu \mathrm{g} / \mathrm{kg} / \mathrm{min})$, and much greater than that used by Battler et al. ${ }^{19}(0.02$ $\mu \mathrm{g} / \mathrm{kg} / \mathrm{min}$ ) Peak heart rate and blood pressures in this study were greater than in prior investigations, ${ }^{19,20,32}$ whereas the peak positive $\mathrm{dP} / \mathrm{dt}$ values were lower, possibly secondary to the effects of anesthesia. Thus the degree of stress induced in the current study was generally comparable to prior studies in chronically instrumented conscious dog models.

Conclusions. There are several clinical implications of this investigation.

1. A diminution in the normal enhancement of regional function caused by isoproterenol can be detected only when coronary reserve is severely impaired. In this investigation, lesions associated with up to an $80 \%$ loss of coronary flow reserve were not associated with regional dysfunction. Furthermore, isoproterenol does not induce a fall in regional shortening compared to resting values unless blood flow is severely impaired. This suggests limited clinical efficacy of isoproterenol stress testing in

detecting mild single-vessel coronary disease when wall motion abnormalities are sought.

2. Impairment of coronary flow reserve at rest is a highly sensitive index of the potential significance of a coronary stenosis. Detection of impairment of this index is more sensitive than the detection of regional dysfunction during an isoproterenol challenge.
3. However, the relation between resting impairments of coronary flow reserve and regional dysfunction during stress is predominantly a function of the actual blood flow during the stress itself. Because the determinants of the hyperemic blood flow are markedly different between rest and stress stages, the relation between coronary flow reserve and regional shortening or other indicators of dysfunction during stress will necessarily vary, depending on the type of stress utilized, the presence of coronary disease in other arteries, and the presence or absence of effective collateral flow during the stress itself. Thus, determination of the ultimate "functional" significance of any lesion should not be made solely on the basis of isolated measures of coronary flow reserve at rest, particularly when this index is only mildly impaired, but should also take into account the actual impact of the lesion during physiologic stress.

We thank Diane Bauer for secretarial assistance.

\section{REFERENCES}

1. Gould KL, Lipscomb K, Hamilton FW. Physiologic basis for assessing critical coronary stenosis. Instantaneous flow response and regional distribution during coronary hyperemia as measures of coronary flow reserve. Am J Cardiol 1975;33:87-94.

2. Marcus M, Wright C, Doty C, et al. Measurement of coronary velocity and reactive hyperemia in the coronary circulation of humans. Circ Res 1981;49:877-91.

3. Wilson RF, Laughlin DE, Ackell PH, et al. Transluminal, subselective measurement of coronary artery blood flow velocity and vasodilator reserve in man. Circulation 1985 ; 72:82-92

4. White $\mathrm{CW}$, Wright $\mathrm{CB}$, Doty $\mathrm{DB}$, et al. Does visual interpretation of the coronary arteriogram predict the physiologic importance of a coronary stenosis? N Engl J Med 1985 310:819-24.

5. O'Riordan JB, Flaherty JT, Donahoo JS, Gott VL. Functional significance of coronary arterial stenoses assessed by regional changes in intramyocardial S-T segment voltage and myocardial gas tensions with atrial pacing. Am J Cardiol 1977;39:529-36.

6. Hodgson JMcB, Mancini GBJ. Relation between graded, subcritical impairments of coronary flow reserve and regional myocardial dysfunction induced by atrial pacing in dogs. $J$ Am Coll Cardiol 1985;5:1116-24.

7. Hodgson JMcB, Mancini GBJ. Relation of coronary blood flow and reactive hyperemia to regional dysfunction induced by dopamine infusion in dogs: limitations in detecting subcritical coronary stenoses. J Am Coll Cardiol 1985;5:664-71.

8. Legrand V, Vogel R, Gross MD, Mancini GBJ. The relationship of coronary flow reserve to stress thallium-201 myocardial perfusion and radionuclide ventriculography [Abstract] J Nucl Med 1984i25i28

9. Vogel R, LeFree M, Bates E, et al. Application of digital techniques to selective coronary arteriography: use of myocardial contrast appearance time to measure coronary flow reserve. AM HEART J 1984;107:153-64

10. Foerster J, Link DP, Lantz BMT, Lee G, Holcroft JW, Mason DT. Measurement of coronary reactive hyperemia during clinical angiography by video dilution techniques. Acta Radiol [Diagn] 1981;22:209-16.

11. Lipton MJ, Higgins CB, Farmer D, Boyd DP. Cardiac 
imaging with a high-speed cine-CT scanner: preliminary results. Radiology 1984;152:579-82.

12. Spiller P, Schmiel FK, Politz B, et al. Measurement of systolic and diastolic flow rates in the coronary artery system by x-ray densitometry. Circulation 1983;689:337-47.

13. Raab W, Lith PV, Lepeschkin E, Herrlich HC, Louis DA. Catecholamine-induced myocardial hypoxia in the presence of impaired coronary dilatability independent of external cardiac work. Am J Cardiol 1962;9:455-70.

14. Krasnow N, Gorlin R. Myocardial lactate metabolism in coronary insufficiency. Ann Intern Med 1963;59:781-87.

15. Daniell HB, Bagwell EE, Walton RP. Limitation of myocardial function by reduced coronary blood flow during isoproterenol action. Circ Res 1967;21:85-98.

16. Griggs DM, Tchokoev VV, DeClue JW. Effect of betaadrenergic receptor stimulation on regional myocardial metabolism: importance of coronary vessel patency. AM Heart J 1971;82:492-502.

17. Buckberg GD, Ross G. Effects of isoprenaline on coronary blood flow: its distribution and myocardial performance. Cardiovasc Res 1973;7:429.

18. McClenathan JH, Guyton RA, Breyer RH, Newman GE, Michaelis LL. The effects of isoproterenol and dopamine on regional myocardial blood flow after stenosis of circumflex coronary artery. J Thorac Cardiovasc Surg 1977;73:431-35.

19. Battler A, Gallagher KP, Froelicher VF, Kumada T, Kemper WS, Ross J Jr. Detection of latent coronary stenosis in conscious dogs: regional functional and electrocardiographic responses to isoprenaline. Cardiovase Res 1980;14:476-81.

20. Gallagher KP, Kumada T, Battler A, Kemper WS, Ross J Jr. Isoproterenol-induced myocardial dysfunction in dogs with coronary stenosis. Am J Physiol 1982;242:H260-7.

21. Krasnow N, Rolett EL, Yurchak PM, Hood WB, Gorlin R. Isoproterenol and cardiovascular performance. Am J Med 1964;37:514-25.

22. Cohen LS, Elliott WC, Klein MD, Gorlin R. Coronary heart disease: clinical, cinearteriographic and metabolic correlations. Am J Cardiol 1966;17:153-68.

23. Wexler H, Kuaity J, Simonson E. Electrocardiographic effects of isoprenaline in normal subjects and patients with coronary atherosclerosis. Br Heart J 1971;33:759-64.

24. Combs DT, Martin CM. Evaluation of isoproterenol as a method of stress testing. AM HEART J 1974;87:711-15.

25. Manca C, Bianchi G, Effendy FN, Bolognesi R, Cucchini F, Visioli $\mathrm{O}$. Comparison of five different stress testing methods in the ECG diagnosis of coronary disease. Correlation with coronary arteriography. Cardiology 1979;64:325-32.

26. Horowitz LD, Curry GC, Parkey RW, Bonte FJ. Differentiation of physiologically significant coronary artery lesions by coronary blood flow measurements during isoproterenol infusion. Circulation 1974;49:55-62.
27. Horwitz LD, Groves BM, Walsh RA, Sorensen SM, Latson TW. Functional significance of coronary collateral vessels in patients with coronary artery disease. AM HEART J 1982; 104:221-225.

28. Abel FL. Maximal negative $\mathrm{dP} / \mathrm{dt}$ as an indicator of end of systole. Am J Physiol 1981;240:H676-9.

29. Neter J, Wasserman W. Applied linear statistical model, Homewood, IL: Richard D. Irwin, Inc, 1974:730.

30. Vatner SF, McRitchie RJ, Maroko PR, Patrick TA, Braumwald E. Effects of catecholamines, exercise and nitroglycerin on the normal and ischemic myocardium in conscious dogs. $J$ Clin Invest 1974;54:563-75.

31. Vatner SF, Millard RW, Patrick TA, Heyndrickx GR. Effects of isoproterenol on regional myocardial function, electrogram and blood flow in conscious dogs with myocardial ischemia. $J$ Clin Invest 1976;57:1261-71.

32. Santamore WP, Walinsky P. Altered coronary flow responses to vasoactive drugs in the presence of coronary arterial stenosis in the dog. Am J Cardiol 1980;45:276-85.

33. Warltier DC, Zyvoloski M, Gross GJ, Hardman HF, Brooks HL. Redistribution of myocardial blood flow distal to a dynamic coronary arterial stenosis by sympathomimetic amines: comparison of dopamine, dobutamine, and isoproterenol. Am J Cardiol 1981;48:269-79.

34. Vatner SF. Correlation between acute reductions in myocardial blood flow and function in conscious dogs. Circ Res 1980;47:201-7.

35. Gallagher KP, Folts JD, Shebuski RJ, Rankin JHG, Rowe GG. Subepicardial vasodilator reserve in the presence of critical coronary stenosis in dogs. Am J Cardiol 1980;46:6773.

36. Gould KL, Lipscomb K, Hamilton GW. Physiologic basis for assessing critical coronary stenosis: instantaneous flow responses and regional distribution during coronary hyperemia as measures of coronary flow reserve. Am J Cardiol 1974;33:87-94.

37. Becker LC. Effect of nitroglycerin and dipyridamole on regional left ventricular blood flow during coronary artery occlusion. J Clin Invest 1976;58:1287-96.

38. Bache RJ, Schwartz JS. Effect of perfusion pressure distal to a coronary stenosis on transmural myocardial blood flow. Circulation 1982;65:928-35.

39. Smalling RW, Kelley K, Kirkeeide RL, Fisher DJ. Regional myocardial function is not affected by severe coronary depressurization provided coronary blood flow is maintained. J Am Coll Cardiol 1985;5:948-55.

40. Gallagher KP, Kumada T, Koziol JA, McKown MD, Kemper WS, Ross J Jr. Significance of regional wall thickening abnormalities relative to transmural myocardial perfusion in anesthetized dogs. Circulation 1980;62:1266-74. 